\title{
MRI-based Annual Cerebellar Volume Atrophy Rate as a Biomarker of Disease Progression in Patients with Cerebellar Degeneration
}

\author{
Shigeaki Tanaka, Futaba Maki, Daisuke Hara, \\ Rie Sasaki, and Yasuhiro Hasegawa
}

(Received for Publication: September 27, 2016)

\begin{abstract}
Background: The rate of disease progression differs among patients with degenerative cerebellar ataxia.

Purpose: We determined the annual cerebellar volume atrophy rate with magnetic resonance imaging (MRI) and disease progression in ataxia with the International Cooperative Ataxia Rating Scale (ICARS) according to the subtype of cerebellar degeneration using longitudinal follow-up data.

Methods: We examined 50 patients consisting of 22 cases of spinocerebellar ataxia (SCA), 17 cases of multiple system atrophy (MSA), and 11 cases of cortical cerebellar ataxia (CCA). In all patients, at least two sets of evaluations including MRI and ICARS scoring were performed. A total of 146 sets of evaluations was obtained with the longest follow-up period being 77 months. The cerebellar volume of all patients $(\mathrm{ml})$ was divided by each cranial AP diameter $(\mathrm{mm})$ to correct for the individual head size differences as a volume index (Vdx). The annual atrophy volume in $\mathrm{Vdx}$ and the annual progression in the ICARS were calculated in each patients.

Results: The annual atrophy rates for each subtype were: SCA: $0.027 \pm 0.020 \mathrm{ml} / \mathrm{mm}$, MSA: $0.039 \pm 0.026$ $\mathrm{ml} / \mathrm{mm}$, and CCA: $0.019 \pm 0.016 \mathrm{ml} / \mathrm{mm}$. There was a significant difference among subtypes $(\mathrm{p}=0.049)$. The ICARS scores (annual progression) were $4.79 \pm 3.86,8.82 \pm 3.93$, and $2.31 \pm 1.96$ for SCA, MSA, and CCA, respectively $(\mathrm{p}=0.002)$. The progression in ICARS per decrease in $\mathrm{Vdx}$ of $0.01 \mathrm{ml} / \mathrm{mm}$ in MSA, SCA and CCA was measured as 5.9 points, 1.8 points and 1.4 points, respectively.

Conclusions: The annual atrophy rate and ICARS score (annual progression) were significantly different among subtypes of cerebellar degeneration. MRI-based cerebellar volume measurements can be used as an imaging biomarker for disease progression.
\end{abstract}

\section{Key words}

MRI, cerebellar volume, spinocerebellar degeneration, multiple system atrophy

\section{Introduction}

The rate of progression differs among patients with degenerative cerebellar ataxia. Many of the subtypes of dominantly inherited spinocerebellar degeneration (SCD) have been named spinocerebellar ataxia (SCA), and the natural histories of patients with the same genotype have been studied. ${ }^{1)}$ However, 10-20\% of cases of dominant SCA are due to unknown mutations, and the rate of progression may vary even in patients with the same genotype. ${ }^{23)}$ Mul- tiple system atrophy (MSA) is another sporadic degenerative disease with cerebellar ataxia as one of the major clinical features. Several clinical trials have been conducted to verify the efficacy of promising drugs. ${ }^{4-6)}$ However, variability among individual clinical courses confounds determination of the most appropriate study design. In addition to early accurate differential diagnosis, establishment of a method to predict future progression in each patient is needed.

In Japan, a nation-wide registry with standardized assessment of all patients with SCD and MSA

Department of Internal Medicine, Division of Neurology, St. Marianna University School of Medicine 
was established in 2003. ${ }^{2)}$ In this registry system, the inquiry sheet includes five items from Parts I and II of the International Cooperative Ataxia Rating Scale (ICARS). ${ }^{7)}$ ICARS scores range from no ataxia (score of 0) to the most severe ataxia (score of 100). A recent systematic review demonstrated that the Posture and Gait sub-component of ICARS describes the most robust psychometric properties with acceptable clinical utility among the 16 rating scales for ataxia. ${ }^{8)}$ In this study, we determined the annual cerebellar volume atrophy rate and the correlation between the atrophy rate and progression, as determined with the ICARS score by retrospective analysis of our longitudinal follow-up data.

\section{Methods}

\section{Patients and methods}

We retrospectively analyzed a database of patients with degenerative cerebellar ataxia who were treated in our hospital from January 2004 to April 2013. A total of 111 patients were followed using a standardized follow-up protocol including magnetic resonance imaging (MRI) and neurological examination with ICARS. Diagnosis of MSA was made in accordance with the second consensus statement including MRI findings. ${ }^{9)}$ Patients with MSA were categorized as MSA with predominant parkinsonism (MSA-P) or MSA with predominant cerebellar ataxia (MSA-C) and classified as definite, probable, or possible based on the levels of certainty. Patients with a family history suggestive of dominant inheritance were diagnosed with SCA. After obtaining informed consent for genetic testing, patients were screened for SCA1, SCA2, SCA3, and SCA6. Further screening for SCA7, SCA8, SCA17, and SCA31 was performed in patients in whom the first screening was negative. When the other rare SCAs were suggested, further studies were performed according to the flow chart suggested by the Study Group on Ataxic Diseases and supported by the Ministry of Health, Labour and Welfare. ${ }^{10)}$ Cortical cerebellar atrophy (CCA) was defined as non-hereditary degenerative ataxia of unknown etiology. ${ }^{21112)}$ The diagnosis of CCA was made based on the following criteria: progressive ataxia; disease onset after 20 years of age; no acute or subacute disease onset; informative and negative family history or no evidence of a causative gene mutation; no established symptomatic cause; and no possible or probable MSA. ${ }^{12)}$

To determine the annual cerebellar volume atrophy rate, we chose 50 patients from our data set using the following inclusion criteria: 1) at least two sets of evaluations including MRI and ICARS scoring were performed, 2) follow-up study was performed after 18 months (allowance, \pm 6 months), 3 ) all MRI scans were performed with the same MRI machine with the same methods, and 4) ICARS scoring was performed on the same day of MRI examination (allowance, \pm 45 days). This study was conducted in a single hospital, and the study protocol was approved by the St. Marianna University Bioethics Committee (No. 2816).

\section{Measurement of cerebellar volume}

Cranial MRI was performed in all patients using a 1.5-T scanner (Achva, Philips, Best Netherland). Brain volume measurement software (TRI/3D-VOL; Ratoc System Engineering, Tokyo, Japan) ${ }^{13) 14}$ was used to measure cerebellar volumes using Digital Imaging and Communications in Medicine (DICOM) data from T1-weighted sagittal images (TE, $15 \mathrm{~ms}$; TR, $520 \mathrm{~ms}$; flip angle, $90^{\circ}$; number of excitations, 3 ; slice thickness, $4 \mathrm{~mm}$; matrix, $272 \times 256$ sagittal sections). We measured each patient's cranial anteroposterior (AP) diameter, defined as the distance between two points at which the skull and the anterior commissure-posterior commissure line intersect. For statistical analysis, the cerebellar volume of all patients was divided by each cranial AP diameter to correct for the individual head size differences as a volume index $(\mathrm{Vdx})$. The normal value of $\mathrm{Vdx}$ in healthy adults (mean age, $64.2 \pm 18.7$ years; Cranial AP diameter, $18.2 \pm 1.1 \mathrm{~cm}$; Body height, $163.5 \pm 6.7$ $\mathrm{cm})$ was $0.65 \pm 0.06 \mathrm{ml} / \mathrm{mm}$. Inter-rater variability and test-retest reliability for the MRI-based cerebellar volume measurements were calculated using 12 randomly selected patients from our data set. Vdx was measured three times by three experienced neurologists who were blinded to the patient's clinical information. The intraclass correlation coefficients were 0.988 for inter-rater variability and 0.994 for test-retest reliability. The annual atrophy volume and the annual progression as measured with the ICARS score were calculated using a linear regression model in each patient.

\section{Statistical analyses}

Characteristics of patients are given as the means and standard deviation (SD), unless otherwise indicated. In each patient, $\mathrm{Vdx}$ at the last follow-up visit was subtracted from the initial $\mathrm{Vdx}$, and this value was divided by the number of follow-up years. Thus, the annual atrophy volume in Vdx was calcula- 
ted for each patient. Similarly, the annual progression in the ICARS score was calculated by using the initial and last ICARS scores. Comparisons among three subgroups were made using ANOVA and post-hoc Bonferroni test. Values of $\mathrm{p}<0.05$ were considered significant. All statistical analyses were performed using SPSS version 22 (IBM SPSS Statistics for Windows; IBM Corp, Armonk, NY).

\section{Results}

A total of 50 patients (24 males; mean age, 60.7 \pm 11.7 years) were examined. Disease subtypes were MSA (17 total patients: 15 with probable MSA-C, one with possible MSA-C, and one with probable MSA-P), CCA (11 patients), and SCA (22 total patients: six with SCA6, four with SCA3, three with SCA2, three with SCA1, one with SCA31, and five for whom the type of SCA was unknown). A total of 146 sets of evaluations was obtained using standardized MRI and ICARS scoring; evaluations were performed up to five times per patient with the longest follow-up period being 77 months.

\section{Patients' characteristics}

Patient characteristics and annual changes in Vdx and ICARS score are shown in Table 1. The mean ages of patients with SCA, MSA, and CCA were slightly different $(\mathrm{p}=0.065): 56.9 \pm 11.2$ years, $60.5 \pm 9.2$ years, and $66.1 \pm 10.2$ years, respectively. The interval of onset to the first MRI examination was significantly different among subtypes $(\mathrm{p}=$
0.004); the interval for MSA was significantly shorter than those for SCA and CCA ( $p=0.005,0.030$, respectively, post-hoc Bonferroni test). The ICARS score, cerebellar volume, and Vdx at the initial evaluation were similar among the three subtypes. The annual atrophy volume in $\mathrm{Vdx}(0.027 \pm 0.020 \mathrm{ml} / \mathrm{mm}$ in SCA, $0.039 \pm 0.026 \mathrm{ml} / \mathrm{mm}$ in MSA, 0.019 $\pm 0.016 \mathrm{ml} / \mathrm{mm}$ in CCA) and the annual progression as determined with the ICARS score $(4.79 \pm 3.86$ in SCA, $8.82 \pm 3.93$ in MSA, $2.31 \pm 1.96$ in CCA) were significantly different among subtypes of cerebellar atrophy ( $p=0.045,0.002$, respectively, ANOVA). The rate of atrophy and the rate of symptom progression were the highest in patients with MSA (post-hoc analysis). The annual atrophy volumes in Vdx converted for the mean normal Japanese adult cranial diameter of $200 \mathrm{~mm}$ were equivalent to $5.4 \pm 4.0 \mathrm{ml}$ in $\mathrm{SCA}, 7.8 \pm 5.2 \mathrm{ml}$ in MSA, and $3.8 \pm 3.2 \mathrm{ml}$ in CCA.

Serial changes in $\mathrm{Vdx}$ and the timing of examination from disease onset were plotted for each subtype (Fig. 1). The mean and SD of $\mathrm{Vdx}$ and the ICARS score at the initial and last follow-ups are plotted in Figure 2. The follow-up periods for each subtype were $27.2 \pm 13.8,22.2 \pm 10.8$, and 20.1 \pm 10.8 months for SCA, MSA, and CCA, respectively. In patients with SCA, the mean Vdx decreased from $0.465 \mathrm{ml} / \mathrm{mm}$ to $0.426 \mathrm{ml} / \mathrm{mm}$, and the mean ICARS score increased from 38 to 45 . Thus, the ICARS score progressed 1.8 points for every decrease in $\mathrm{Vdx}$ of $0.01 \mathrm{ml} / \mathrm{mm}$. A Vdx of $0.01 \mathrm{ml} / \mathrm{mm}$ is equivalent to $2 \mathrm{ml}$ for the normal Japanese adult

Table 1. Patients' Characteristics and Annual Changes in Cerebellar Volume and ICARS Score

\begin{tabular}{lcccc}
\hline & $\begin{array}{c}\text { SCA } \\
(\mathrm{n}=22)\end{array}$ & $\begin{array}{c}\text { MSA } \\
(\mathrm{n}=17)\end{array}$ & $\begin{array}{c}\text { CCA } \\
(\mathrm{n}=11)\end{array}$ & p value \\
\hline Age at the first MRI & $56.9 \pm 11.2$ & $60.5 \pm 9.2$ & $66.1 \pm 10.2$ & 0.065 \\
Sex (Male /Female) & $12 / 10$ & $8 / 9$ & $4 / 7$ & 0.613 \\
Interval of onset to the first MRI (month) & $119.5 \pm 75.2$ & $51.8 \pm 39.7^{*}$ & $117.5 \pm 66.0$ & 0.004 \\
ICARS score at the 1 ${ }^{\text {st }}$ visit & $33.0 \pm 12.9$ & $36.8 \pm 22.2$ & $35.0 \pm 12.4$ & 0.889 \\
Initial cerebellum volume (ml) & $84.5 \pm 16.9$ & $84.6 \pm 17.3$ & $83.6 \pm 18.4$ & 0.980 \\
Initial cerebellar volume index (Vdx) & $0.49 \pm 0.10$ & $0.45 \pm 0.08$ & $0.48 \pm 0.08$ & 0.392 \\
Annual atrophy volume in Vdx & $0.027 \pm 0.020$ & $0.039 \pm 0.026^{\ddagger}$ & $0.019 \pm 0.016$ & 0.049 \\
Annual progression in ICARS score & $4.79 \pm 3.86$ & $8.82 \pm 3.93^{\dagger}$ & $2.31 \pm 1.96$ & 0.002 \\
\hline
\end{tabular}

Vdx indicates cerebellar volume index $(\mathrm{ml} / \mathrm{mm})$; ICARS, the International Cooperative Ataxia Rating Scale *: SCA vs MSA, $p=0.005$, CCA vs MSA, $p=0.030$; $\ddagger$ : MSA vs CCA, $p=0.04$; $\uparrow$ : SCA vs MSA, $=0.045$, CCA vs MSA, $\mathrm{p}=0.002$ (posthoc Bonferroni test) 

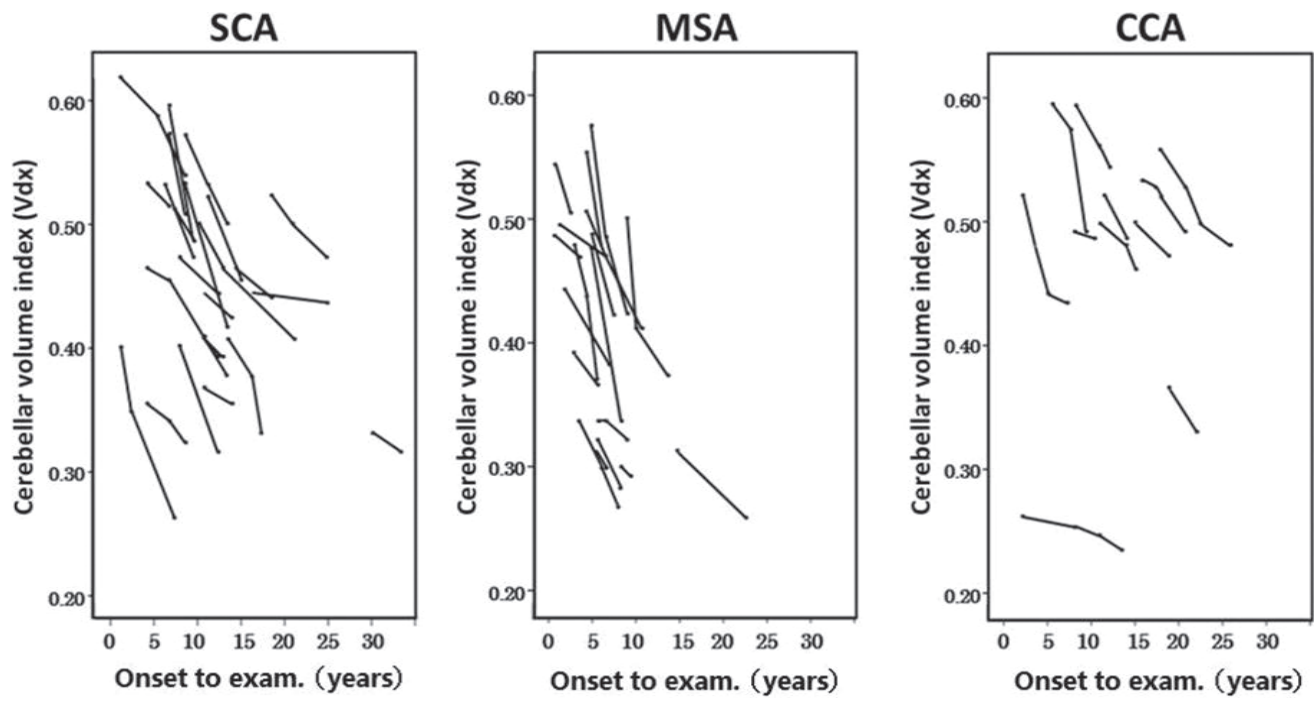

Figure 1. Correlation between amount of initial atrophy and the subsequent annual atrophy rate

Serial changes in Vdx and the timing of examination from disease onset were plotted for each subtype.
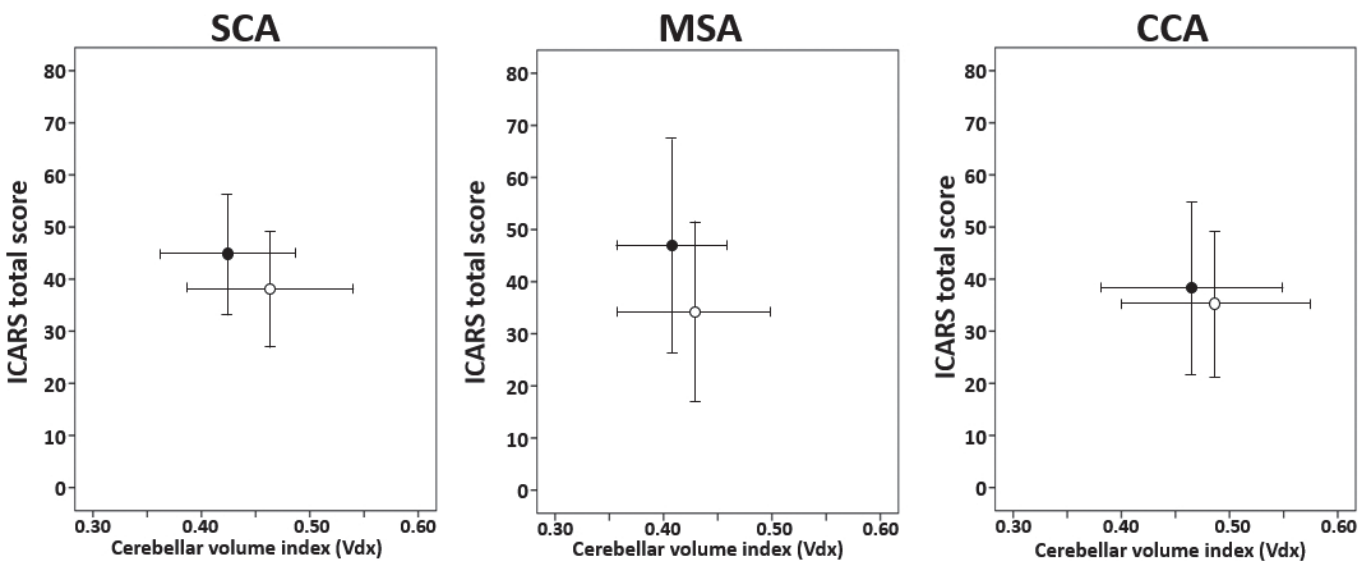

Figure 2. Changes in cerebellar volume and ICARS score between the initial and last follow-ups Mean and SD of Vdx and ICARS score at the initial (open circle) and last follow-ups (closed circle) were plotted.

cranial diameter $(200 \mathrm{~mm})$. Similarly, progression in ICARS per decrease in Vdx of $0.01 \mathrm{ml} / \mathrm{mm}$ in MSA and CCA was measured as 5.9 points and 1.4 points, respectively. Thus, the symptom progression per unit volume of cerebellar atrophy was the highest in MSA patients.

\section{Discussion}

Our study is the first report on the actual atrophy volume and symptom progression in different subtypes of cerebellar ataxia in Japanese patients. Our study was a retrospective analysis of long-term
ICARS and MRI follow-up data. The results showed that the annual cerebellar atrophy rate differed by subtype. When corrected for mean cranial diameter in Japanese adults $(200 \mathrm{~mm})$, the annual atrophy volume was the greatest for MSA $(5.4 \pm 4.0 \mathrm{ml}$ in SCA, $7.8 \pm 5.2 \mathrm{ml}$ in MSA, and $3.8 \pm 3.2 \mathrm{ml}$ in CCA). The ICARS annual progression rate was also the highest for MSA, with an annual increase of 8.82 points. This progression rate was significantly higher than that for SCA and CCA. The ICARS progression rate per unit volume of cerebellar atrophy was also highest for MSA, followed by SCA and CCA. The rapid increase 
in ICARS scores in MSA patients can be attributed to the fact that MSA is a subtype that causes atrophy of multiple systems other than just the cerebellum. However, the rate of atrophy of the cerebellum itself in MSA also tended to be higher than that in SCA and CCA.

MRI-based cerebellar volume measurements can be used to quantify the decrease in volume due to cerebellar atrophy ${ }^{15)}$, which is difficult to evaluate with visual qualitative assessment alone. This can be used as an imaging biomarker for disease progression. Although studies of patients with degenerative cerebellar diseases, including patients with $\mathrm{MSA}^{16)}$ and SCA1, SCA3, and SCA6 ${ }^{17}$, have also been performed, few have been large-scale studies.

Various drugs are now being developed to treat degenerative cerebellar ataxia ${ }^{4-6)}$, but designing clinical trials has been challenging because early diagnosis is difficult, and progression rates differ depending on the subtype. Intervention studies using the Scale for Assessment and Rating of Ataxia (SARA) ${ }^{18)}$ and the Unified Multiple System Atrophy Rating Scale $(\mathrm{UMSARS})^{5{ }^{19)}}$ for assessment have been conducted. In addition, disease-specific scoring scales such as $\mathrm{ICARS}^{7}$, $\mathrm{UMSARS}^{20)}$, and SARA ${ }^{21}$, as well as MRIbased measured values ${ }^{22)}$, volume ${ }^{17)}$, morphometry ${ }^{2324)}$, and biomarkers ${ }^{2526)}$, have been investigated as surrogate markers. However, 300 cases $^{27)}$ are required to detect an annual progression rate of $50 \%$ using SARA, and 250 cases $^{21)}$ are required to detect an annual progression rate of $80 \%$ using UMSARS ${ }^{28}$. Therefore, these studies require a relatively large patient population.

The annual cerebellar volume atrophy rate might not be necessarily the same throughout the disease course. A ceiling effect might be appear, especially in its later phase. Treatment for neurodegenerative diseases may be efficacious if it is begun in the earlier stage before reaching its full extent. Our study, which examined sequential changes in $\mathrm{Vdx}$ from the time of disease onset, demonstrated a more rapid decline in Vdx from the initial stage in MSA than in SCA and CCA (Fig. 1). The rate of symptom progression was slower in CCA patients, and their rate of decline in $\mathrm{Vdx}$ was more gradual. Annual declines in Vdx, i.e. the slopes of lines in Figure 1, in each subtype are found to be similar with a broad range of the initial Vdx value.

Among patients clinically diagnosed with MSA at an early stage of disease, $7.3 \%$ were later found to have an SCA gene mutation. ${ }^{29)}$ Thus, early diagnosis of subtypes is not easy. However, imaging markers can be evaluated in the same manner in multiple facilities, and current imaging analysis technology makes it easy to quantify changes. Our study results suggest that assessing the rate of $\mathrm{Vdx}$ decline in early-stage patients who have little brain atrophy can be used to predict subsequent disease progression. This may be useful in designing randomized clinical trials to investigate the efficacy of drug treatment. Conducting future prospective studies with a larger number of patients would be most worthwhile.

Our study has some limitations. First, our study was a retrospective analysis using longitudinal follow-up data from previously diagnosed SCD and MSA patients. Brain MRI and ICARS scores were assessed around the same time, the study period was not established beforehand, and no prospective data were collected. Therefore, the follow-up periods and number of examinations differed among patients. Second, the time of onset was based on the medical history given by each patient, the number of years from onset varied, and some patients had severe cerebellar atrophy only a few years after onset. Thus, specifying the time of onset was challenging. Third, we retrospectively analyzed 2D MRI data with $4 \mathrm{~mm}$ in slice thickness obtained by routine examination. MRI-based cerebellar volume measurement still remains challenging, due to its morphological complexity such as thin sulci and gyri. However, several sophisticated MRI methods have been reported for the measurement of cerebellar volume $\mathrm{e}^{30-34)}$, and nowadays it is easy to obtain high-resolution 3D MRI imaging. Fourth, we need to consider variation or diversity of disease progression among different subtypes of degenerative cerebellar ataxia. Even in patients with the same gene mutation and stage of the disease, phenotypic variability may exist. In this study, analysis by SCA genotype was not possible because of the limited number of patients. Autopsy studies in $\mathrm{MSA}^{35)}$ have shown ethnic differences, namely, more pontine atrophy in Japanese MSA and more basal ganglia degeneration in British MSA. In addition, MSA-C accounts for $\geq 60 \%$ of cases in Japan, whereas MSA-P accounts for $79.2 \%$ of cases in Western countries. Because of differences in genetic backgrounds, our results cannot be generalized to Western patients. The concept of CCA as a disease is somewhat ambiguous. CCA is not necessarily sporadic, and the differential diagnosis from MSA-C in the early stages is difficult. ${ }^{13)}$ This may be a mixed disease entity with recessive inheritance or dominant in- 
heritance with very low penetrance. ${ }^{13)}$ Determining the genotype whenever possible and controlling for the severity of cerebellar atrophy and clinical findings such as ICARS scores are important in designing clinical trials.

\section{References}

1) Jacobi H, Bauer P, Giunti $P$, Labrum R, Sweeney MG, Charles P, Dürr A, Marelli C, Globas C, Linnemann C, Schöls L, Rakowicz M, Rola R, Zdzienicka E, Schmitz-Hübsch T, Fancellu R, Mariotti C, Tomasello C, Baliko L, Melegh B, Filla A, Rinaldi C, van de Warrenburg BP, Verstappen CCP, Szymanski S, Berciano J, Infante J, Timmann D, Boesch S, Hering S, Depondt C, Pandolfo M, Kang JS, Ratzka S, Schulz J, Tezenas du Montcel S, Klockgether T. The natural history of spinocerebellar ataxia type 1, 2, 3, and 6: a 2-year follow-up study. Neurology 2011; 77: 1035-1041.

2) Tsuji S, Onodera $O$, Goto J, Nishizawa M. Sporadic ataxias in Japan--a population-based epidemiological study. Cerebellum 2008; 7: 189-197.

3) Sakakibara S, Aiba I, Saito Y, Inukai A, Ishikawa K, Mizusawa H. Clinical features and MRI findings in spinocerebellar ataxia type 31 (SCA31) comparing with spinocerebellar ataxia type 6 (SCA6). Rinsho Shinkeigaku 2014; 54: 473-479.

4) Biaggioni I, Freeman R, Mathias CJ, Low P, Hewitt LA, Kaufmann H. Randomized withdrawal study of patients with symptomatic neurogenic orthostatic hypotension responsive to droxidopa. Hypertension 2015; 65: 101-107.

5) Poewe W, Seppi K, Fitzer-Attas CJ, Wenning GK, Gilman S, Low PA, Giladi N, Barone P, Sampaio C, Eyal E, Rascol O. Efficacy of rasagiline in patients with the parkinsonian variant of multiple system atrophy: a randomised, placebo-controlled trial. Lancet Neurol 2015; 14: 145-152.

6) Lee PH, Lee JE, Kim HS, Song SK, Lee HS, Nam HS, Cheong JW, Jeong Y, Park HJ, Kim DJ, Nam CM, Lee JD, Kim HO, Sohn YH. A randomized trial of mesenchymal stem cells in multiple system atrophy. Ann Neurol 2012; 72: 32-40.

7) Trouillas $P$, Takayanagi $T$, Hallett M, Currier RD, Subramony SH, Wessel K, Bryer A, Diener HC, Massaquoi S, Gomez CM, Coutinho P, Ha- mida MB, Campanella G, Filla A, Schut L, Timann D, Honnorat J, Nighoghossian N, Manyam B. International Cooperative Ataxia Rating Scale for pharmacological assessment of the cerebellar syndrome. The Ataxia Neuropharmacology Committee of the World Federation of Neurology. J Neurol Sci 1997; 145: 205-211.

8) Winser SJ, Smith CM, Hale LA, Claydon LS, Whitney SL, Mehta P. Systematic review of the psychometric properties of balance measures for cerebellar ataxia. Clin Rehabil 2015; 29: 69-79.

9) Gilman S, Wenning GK, Low PA, Brooks DJ, Mathias CJ, Trojanowski JQ, Wood NW, Colosimo C, Dürr A, Fowler CJ, Kaufmann H, Klockgether T, Lees A, Poewe W, Quinn N, Revesz T, Robertson D, Sandroni P, Seppi K, Vidailhet M. Second consensus statement on the diagnosis of multiple system atrophy. Neurology 2008; 71: 670-676.

10) Spinocerebellar degeneration [homepage on the internet]. Japan: Information center of specific pediatric chronic diseases. [updated 2014 Oct 1:cited 2016 Feb 2]. Available from: http:// www.shouman.jp/details/11_18_51.html

11) Abele M, Burk K, Schols L, Schwartz S, Besenthal I, Dichgans J, Zühlke C, Riess O, Klockgether T. The aetiology of sporadic adult-onset ataxia. Brain 2002; 125: 961-968.

12) Klockgether T. Sporadic adult-onset ataxia of unknown etiology. Handb Clin Neurol 2012; 103: 253-262.

13) https://www.ratoc.co.jp/pap_c.html.

14) Sato F, Nakamura Y, Shinoda Y. Three-dimensional analysis of cerebellar terminals and their postsynaptic components in the ventral lateral nucleus of the cat thalamus. J Comp Neurol 1996; 371: 537-551.

15) Hara D, Maki F, Tanaka S, Sasaki R, Hasegawa Y. MRI-based cerebellar volume measurements correlate with the International Cooperative Ataxia Rating Scale score in patients with spinocerebellar degeneration or multiple system atrophy. Cerebellum \& Ataxias 2016; 3: 14.

16) Hauser TK, Luft A, Skalej M, Nagele T, Kircher TT, Leube DT, Schulz JB. Visualization and quantification of disease progression in multiple system atrophy. Mov Disord 2006 Oct; 21: 1674-1681.

17) Reetz K, Costa AS, Mirzazade S, Lehmann A, Juzek A, Rakowicz M, Boguslawska R, Schöls L, Linnemann C, Mariotti C, Grisoli M, Dürr A, 
van de Warrenburg BP, Timmann D, Pandolfo M, Bauer P, Jacobi H, Hauser TK, Klockgether T, Schulz JB and the Ataxia Study Group Investigators. Genotype-specific patterns of atrophy progression are more sensitive than clinical decline in SCA1, SCA3 and SCA6. Brain 2013; 136: 905-917.

18) Romano S, Coarelli G, Marcotulli C, Leonardi L, Piccolo F, Spadaro M, Frontali M, Ferraldeschi M, Vulpiani mc, Ponzelli F, Salvetti M, Orzi F, Petrucci A, Vanacore N, Casali C, Ristori G. Riluzole in patients with hereditary cerebellar ataxia: a randomised, double-blind, placebo-controlled trial. Lancet Neurol 2015; 14: 985-991.

19) Low PA, Robertson D, Gilman S, Kaufmann H, Singer W, Biaggioni I, Freeman R, Perlman S, Hauser RA, Cheshire W, Lessig S, Vernino S, Mandrekar J, Dupont WD, Chelimsky T, Galpern WR. Efficacy and safety of rifampicin for multiple system atrophy: a randomised, doubleblind, placebo-controlled trial Lancet Neurol 2014; 13: 268-275.

20) Wenning GK, Tison F, Seppi K, Sampaio C, Diem A, Yekhlef F, Ghorayeb I, Ory F, Galitzky M, Scaravilli T, Bozi M, Colosimo C, Gilman S, Shults CW, Quinn NP, Rascol O, Poewe W and the Multiple System Atrophy Study Group. Development and validation of the Unified Multiple System Atrophy Rating Scale (UMSARS). Mov Disord 2004; 19: 1391-1402.

21) Schmitz-Hubsch T, du Montcel ST, Baliko L, Berciano J, Boesch S, Depondt C, Giunti P, Globas C, Infante J, Kang JS, Kremer B, Mariotti C, Szymanski S, van de Warrenburg BP, Dürr A, Klockgether T. Scale for the assessment and rating of ataxia: development of a new clinical scale. Neurology 2006; 66: 1717-1720.

22) Brooks DJ, Seppi K. Proposed neuroimaging criteria for the diagnosis of multiple system atrophy. Mov Disord 2009; 24: 949-964.

23) Specht K, Minnerop M, Abele M, Reul J, Wullner $\mathrm{U}$, Klockgether $\mathrm{T}$. In vivo voxel-based morphometry in multiple system atrophy of the cerebellar type. Arch Neurol 2003; 60: 14311435.

24) Mascalchi M, Diciotti S, Giannelli M, Ginestroni A, Soricelli A, Nicolai E, Aiello M, Tessa C, Galli L, Dotti MT, Piacentini S, Salvatore E, Toschi N. Progression of brain atrophy in spinocerebellar ataxia type 2: a longitudinal tensor- based morphometry study. PLoS One 2014; 9: e89410.

25) Holmberg B, Johnels B, Ingvarsson $P$, Eriksson $\mathrm{B}$, Rosengren L. CSF-neurofilament and levodopa tests combined with discriminant analysis may contribute to the differential diagnosis of Parkinsonian syndromes. Parkinsonism Relat Disord 2001; 8: 23-31.

26) Sasaki H, Matsushima M, Hama Y, Sakushima K, Nakamura M, Yabe I, Oba K, Tanji K, Mori F, Wakabayashi K, Kakita A, Takahashi H, Utsumi J. Plasma matrix metalloproteinase-3 correlates with the clinical severity in men with multiple system atrophy. Neurology and Clinical Neuroscience 2013; 1: 69-77.

27) Schmitz-Hubsch T, Fimmers R, Rakowicz M, Rola R, Zdzienicka E, Fancellu R, Mariotti C, Linnemann C, Schöls L, Timmann D, Filla A, Salvatore E, Infante J, Giunti P, Labrum R, Kremer B, van de Warrenburg BPC, Baliko L, Melegh B, Depondt C, Schulz J, du Montcel ST, Klockgether T. Responsiveness of different rating instruments in spinocerebellar ataxia patients. Neurology 2010; 74: 678-684.

28) Wenning GK, Geser F, Krismer F, Seppi K, Duerr S, Boesch S, Köllensperger M, Goebel G, Pfeiffer K, Barone P, Pellecchia MT, Quinn N, Koukouni V, Flower C, Schrag A, Mathias CJ, Giladi N, Gurevich T, Dupont E, Ostergaard K, Nilsson CF, Widner H, Oertel W, Eggert KM, Albanese A, del Sorbo F, Tolosa E, Cardozo A, Deuschl G, Hellriegel H, Klockgether T, Dodel R, Sampaio C, Coelho M, Djaldetti R, Melamed E, Gasser T, Kamm C, Meco G, Colosimo C, Rascol O, Meissner WG, Tison F, Poewe W. The natural history of multiple system atrophy: a prospective European cohort study. Lancet Neurol 2013; 12: 264-274.

29) Kim HJ, Jeon BS, Shin J, Lee WW, Park H, Jung YJ, Ehm G. Should genetic testing for SCAs be included in the diagnostic workup for MSA? Neurology 2014; 83: 1733-1738.

30) Lukas C, Bellenberg B, Köster O, Greschner S, Hahn HK. A new sulcus-corrected approach for assessing cerebellar volume in spinocerebellar ataxia. Psychiatry Res 2011; 193: 123-130.

31) Luft AR, Skalej M, Schulz JB, Welte D, Kolb R, Bürk K, Klockgether T, Voigt K. Patterns of age-related shrinkage in cerebellum and brainstem observed in vivo using three-dimensional MRI volumetry. Cereb Cortex 1999; 9: 712- 
721.

32) Jung BC, Choi SI, Du AX, Cuzzocreo JL, Ying HS, Landman BA, Perlman SL, Baloh RW, Zee DS, Toga AW, Prince JL, Ying SH. MRI shows a region-specific pattern of atrophy in spinocerebellar ataxia type 2. Cerebellum 2012; 11: 272279.

33) Stefanescu MR, Dohnalek M, Maderwald S, Thürling M, Minnerop M, Beck A, Schlamann M, Diedrichsen J, Ladd ME, Timmann D. Structural and functional MRI abnormalities of cerebellar cortex and nuclei in SCA3, SCA6 and Friedreich's ataxia. Brain 2015; 138(Pt 5):
1182-1197.

34) Hernandez-Castillo CR, Galvez V, Diaz R, Fernandez-Ruiz J. Specific cerebellar and cortical degeneration correlates with ataxia severity in spinocerebellar ataxia type 7. Brain Imaging Behav 2016; 10: 252-257.

35) Ozawa T, Revesz T, Paviour D, Lees AJ, Quinn N, Tada M, Kakita A, Onodera O, Wakabayashi K, Takahashi H, Nishizawa M, Holton JL. Difference in MSA phenotype distribution between populations: genetics or environment? J Parkinsons Dis 2012; 2: 7-18. 